\section{An editor speaks for himself: A retrospective view}

"As you may have noted, the American Osteopathic Association has a new editor." Such was the introduction to my editorship as it began in the September 1961, JOURNAL OF THE AMERICAN OSTEOPATHIC ASSOCIATION with the first editorial, "An editor speaks for himself." In retrospect, it's been a rich and rewarding experience for me. To be both spectator and participant in the growth of our profession for so long has been an opportunity I shall always cherish. Twenty-six years ago, I wrote, "Your Editor believes in the future of the osteopathic profession. He believes that osteopathic medicine has a contribution to make that has not been fully made. He does not believe that its contribution is solely to physical medicine, nor does he believe it to be limited to the confines of that term. He believes that the osteopathic school of practice is more than a performance of a therapy, more than the development of a diagnostic technique, and more than an episode in the "continuum of medicine." With equal sincerity I can say the same in 1987.

Any strength that this particular editorship may have had is in direct proportion to the support not only of the organization itself and its officers, but of the profession at large. The free and easy communication that I have enjoyed with so many of you in the profession has always stimulated my desire to do better and provide the AOA with publications of which it could be proud.

As we welcome Thomas Wesley Allen, D.O., as the new Editor in Chief, we do so with great hopes that he will lift our publications to an even higher level of usefulness and scientific standing. Dr. Allen brings to the editorship the type of knowledge, experience, and understanding to speak well for the profession. He will be successful if he receives the same kind of support and encouragement you have given me.

The new AOA building and headquarters symbolize the growth experienced by the profession and also serve as a guiding light to its future. Someone's track coach once admonished his runners to "get out in front and then increase your position." So may it be with our profession.

In closing, I think what I wrote 26 years ago (with a bit of editorial license as your editor) contains the thoughts with which I would like to leave you. "I have, within the limits of my ability, attempted to speak clearly and without fear. I have tried to be creative rather than merely provocative. I make no pretext of avoiding emotion, because I do not believe that emotion is a disease. I believe that it was enthusiasm, and faith, and hopefulness when things looked hopeless, that brought this profession to its greatest success. I believe that complete objectivity without loyalty, faith, and creativeness is a vacuum into which failure can move.

"I tried to speak with humility but with confidence. And that confidence lay not so much in myself as in the profession that I have tried to serve. My desire is to see that the profession is provided with the facts for decision but also with understanding. For knowledge without understanding can become our most destructive force."

Thank you all for allowing me the privilege to serve.

GEORGE W. NORTHUP, D.O., FAAO

\section{Contributing editors join JAOA}

THE JOURNAL OF THE AMERICAN OSTEOPATHIC ASSOCIATION is pleased to welcome Gilbert E. D'Alonzo, Jr., D.O., and Michael M. Patterson, Ph.D., as new contributing editors. Their appointment, approved by the Board of Trustees of the AOA, is part of our continuing effort to meet the needs of the osteopathic medical profession and JAOA readers by improving the scholarly quality of this publication.

Dr. D'Alonzo, a graduate of the Philadelphia College of Osteopathic Medicine, is presently assistant professor of medicine at the University of Texas Medical School in Houston. He completed a rotating internship and residency in internal medicine at Detroit Osteopathic and BiCounty Community Hospitals and served a three-year fellowship in 